\title{
Hand Preferences in Two Unimanual and Two Bimanual Coordinated Tasks in the Black-Handed Spider Monkey (Ateles geoffroyi)
}

Alba Motes Rodrigo, Carlos Eduardo Ramirez Torres, Laura Teresa Hernandez Salazar and Matthias Laska

The self-archived postprint version of this journal article is available at Linköping University Institutional Repository (DiVA):

http:// urn.kb.se/ resolve?urn=urn:nbn:se:liu:diva-148147

N.B.: When citing this work, cite the original publication.

Rodrigo, A. M., Ramirez Torres, C. E., Hernandez Salazar, L. T., Laska, M., (2018), Hand Preferences in Two Unimanual and Two Bimanual Coordinated Tasks in the Black-Handed Spider Monkey (Ateles geoffroyi), J ournal of comparative psychology (1983), 132(2), 220-229.

https:// doi.org/ 10.1037/ com0000110

Original publication available at:

https:// doi.org/ 10.1037/ com0000110

Copyright: American Psychological Association

http:// www.apa.org/ 


\section{Hand preferences in two unimanual and two bimanual}

\section{coordinated tasks in the black-handed spider monkey,}

Ateles geoffroyi

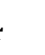

\section{Author footnotes:}

9 We thank Gildardo Castañeda and Jorge Jauregui for help with the data collection and for expert maintenance of our study animals. We also thank Maribel Rodrigo Aleixandre for her

1 help with the data collection and for private funding of the project, as well as "Obra Social la

2 Caixa" for funding during AMR formal training.

3 Correspondence concerning this article should be addressed to Matthias Laska, IFM Biology, 4 Linköping University, SE-581 83 Linköping, Sweden. E-mail: malas@ifm.liu.se 


\section{Abstract}

26 Spider monkeys are interesting to study with regard to hand preferences as they are one of the

27 few primate species lacking a thumb and thus unable of performing a precision grip. Further,

28 being platyrrhine primates, they also largely lack independent motor control of the digits and

29 thus have only limited manual dexterity. It was therefore the aim of the present study to 30 assess hand preferences in black-handed spider monkeys (Ateles geoffroyi) in four tasks 31 differing in task demand: simple unimanual reaching for food, and three versions of the 32 widely-used tube task, including two bimanual versions which differ from each other in the 33 degree of fine motor control needed, and a unimanual version which does not require 34 coordinated action of the hands. We found that black-handed spider monkeys display 35 significant hand preferences at the individual, but not at the population level. This was true both in the two bimanual coordinated tasks and in the two unimanual tasks. Further, our results show that the majority of animals was consistent in the hand they preferred in these four tasks. Our findings only partially support the notion that task demand positively correlates with strength of hand preference. Finally, we found that the index finger was the most-frequently used digit in all three tube tasks, although the animals also used other digits and two- and three-finger combinations to extract food from a tube. We conclude that limited manual dexterity does not prevent spider monkeys from displaying strong and consistent hand preferences at the individual level.

45 Keywords: Ateles geoffroyi, hand preferences, laterality, spider monkey, tube task 


\section{Introduction}

47 Numerous studies on manual laterality in nonhuman primates have found that tasks requiring fine motor skills or bimanual coordination of motor actions are more likely to elicit hand preferences compared to more simple, usually unimanual tasks such as reaching (e.g. Meguerditchian et al., 2013; Hopkins et al., 2015). Some authors even make a distinction between "low-level" and "high-level" tasks, depending on the degree of task demand (e.g. Fagot \& Vauclair, 1991; Lilak \& Phillips, 2008). However, it is difficult to define a boundary between such categories and it is difficult to define a valid measure of the degree of task demand, particularly when trying to compare between tasks that require different types of fine motor skills (e.g. tool use versus precision grip). Furthermore, it should be emphasized that although certain tasks may be more likely to elicit hand preferences than others, all tasks are equally important if we want to make a statement as to whether an individual displays manual specialization or a species displays true handedness according to the now widely accepted definitions introduced by McGrew and Marchant (1997).

The tube task is a frequently used means to assess primate hand preference in a coordinated bimanual motor pattern (e.g. Hopkins et al., 2011, in chimpanzees, bonobos, gorillas, and orangutans; Westergaard \& Suomi, 1996, in tufted capuchins and rhesus macaques; Meguerditchian et al., 2012, in squirrel monkeys; Maille et al., 2013, in De Brazza’s monkeys and red-capped mangabeys; Morino et al., 2017, in siamangs and white-cheeked gibbons). In this task, the inner surface of a tube is baited with a sticky food (e.g. peanut butter, honey, or avocado paste) and then presented to an animal. In order to retrieve the food, an animal has to hold the tube with one hand and to insert the other hand, or finger(s) of the other hand, into the tube. By convention, the hand performing the motor pattern requiring the higher degree of precision, that is, the hand whose fingers are inserted into the tube, is recorded. Similar to other tasks that require bimanual coordination and/or fine motor skills, 
71 the tube task has been found to usually elicit stronger hand preferences compared to simple unimanual tasks such as unconstrained reaching for food from a flat surface (e.g. Canteloup et al., 2013; Lilak \& Phillips, 2008; Schmitt et al., 2008; Spinozzi et al., 1998).

74 Spider monkeys (genus Ateles) are particularly interesting to study with regard to hand preferences as they are one of the few primate species lacking a thumb (Ankel-Simons, 2007). Being platyrrhine primates, they also largely lack independent motor control of the digits (capuchin monkeys being an exception among platyrrhines in this respect) which limits their ability to perform precision grips (Fragaszy \& Crast, 2016). Thus, not surprisingly, spider monkeys have been reported to prefer using their mouth rather than their hand to retrieve small food items from the floor when they have the opportunity to choose between these two options (Laska, 1996a). Nevertheless, a recent study found that Colombian spider monkeys (Ateles fusciceps rufiventris) are clearly able to perform the tube task and that they display significant hand preferences at the individual, but not at the population level in this task (Nelson et al., 2015). A follow-up study confirmed this finding and further reported that the inner diameter of the tube systematically affected the strength, but not the direction of hand preference which is consistent with the notion that task complexity or the degree of fine motor skills required correlate positively with the expression of hand preference (Nelson \& Boeving, 2015).

Only few studies that employed the tube task so far assessed which finger(s) a primate uses for food retrieval when the inner diameter of the tube prevents the animal from inserting its whole hand (e.g. Meunier \& Vauclair, 2007, in white-faced capuchins; Vauclair et al., 2005, in olive baboons; Nelson et al., 2015, in Colombian spider monkeys). This, however, should be interesting for at least two reasons: firstly, to further corroborate the presumed correlation between task complexity or fine motor skill and the strength of hand preference, and 
95 secondly, to gain further insight into the role that independent motor control of the digits may

96 play for the expression of hand preference.

97 It was therefore the aim of the present study to assess hand preferences in black-handed 98 spider monkeys (Ateles geoffroyi). More specifically, we compared their performance 99 between a simple unimanual food reaching task and two versions of the coordinated bimanual 100 tube task which differ from each other in the degree of fine motor control needed. 101 Additionally, we assessed whether hand preference in the bimanual tube tasks differed from 102 hand preference in a unimanual tube task, that is, a task that does not require an animal to 103 hold the tube while inserting its finger(s) for retrieving food. In all tasks involving a tube, we 104 also assessed which digits the animals used for food retrieval and the posture that the animals 105 adopted.

\section{Materials and Methods}

\section{Subjects}

109 Testing was carried out using 14 adult black-handed spider monkeys (Ateles geoffroyi), seven 110 males and seven females. The animals were kept in outdoor enclosures at the UMA Doña 111 Hilda Ávila de O’Farrill (Environmental Management Unit), maintained by the Universidad 112 Veracruzana near Catemaco, Veracruz, Mexico, and were thus exposed to natural 113 environmental conditions concerning ambient temperature, relative humidity, and light.

114 The animals were fed once a day fresh fruits and vegetables after the daily test sessions 115 described below. The amount of food offered daily was such that left-overs were still present 116 on the floor the next morning and thus it was unlikely that ravenous appetite affected the 117 animals' behavior during the tests.

118 The experiments reported here comply with the Guide for the Care and Use of Laboratory 119 Animals ( $8^{\text {th }}$ edition, National Research Council, 2011), the American Society of 
120 Primatologists' Principles for the Ethical Treatment of Primates, and also with current

121 Swedish and Mexican laws. They were performed according to a protocol approved by the

122 Ethical Board of the Federal Government of Mexico's Secretariat of Environmental and

123 Natural Resources (SEMARNAT; Official permits no. 09/GS-2132/05/10).

124

\section{Procedure}

126 Each individual was presented with four tasks:

127 Bimanual Big Tube task: Grasping an opaque PVC tube (length: $20 \mathrm{~cm}$, inner diameter: 23

$128 \mathrm{~mm}$ ) with one hand the animal introduced any number of fingers of the other hand inside the

129 tube to retrieve the avocado paste placed inside. The tube was connected to a thin rope which

130 allowed the experimenter to retrieve the tube easily. The individuals could adopt any body 131 position they preferred.

132 Bimanual Small Tube task: Same procedure as the Big Tube task with a smaller tube (opaque 133 PVC, length: $20 \mathrm{~cm}$, inner diameter, $13 \mathrm{~mm}$ ).

134 Each task with a big or a small tube was performed as follows: a tube was inserted into a cage

135 at varying locations of the mesh, letting it fall to the floor hanging from the rope, taking care 136 that the experimenter used both hands alternatively. The animals could grasp the tube at any

137 moment (while inserting the tube, while the tube was hanging, or while the tube was lying on 138 the floor). After an animal had grasped the tube and extracted the food reward from its inside, 139 the tube was retrieved from the cage using the attached rope and refilled. A bout started when 140 the animal first grasped the tube and ended when the animal dropped the tube and the 141 experimenter pulled the tube back. The animals completed 100 bouts per task. Twenty bouts, 142 separated in two groups of ten bouts one hour apart, were recorded for each individual on a 143 given day. For each individual, the first 50 bouts with the big tube were recorded at the 144 beginning of the experimental period, while the second 50 bouts were recorded after the 
145 animals had completed their 100 bouts with the small tube. This was done in order to assess

146 if the bouts with the small tube, which required a higher degree of motor control to retrieve

147 the food influenced the performance of the animals with the motorically less demanding big 148 tube.

149 Unimanual Tube task: One of the big tubes was mounted perpendicular onto the center of a $15030 \times 30 \mathrm{~cm}$ metal plate so that its inner diameter of $23 \mathrm{~mm}$ matched an equally-sized hole in 151 the plate. The metal plate was then attached to the outside of the mesh of an enclosure, with 152 the tube protruding towards the experimenter. Care was taken that the opening of the plate, 153 and thus the opening of the tube, matched one of the mesh openings so that an animal could 154 reach into the tube. The animals introduced any number of fingers into the tube to retrieve the 155 avocado paste. No holding of the tube was possible as the animals could not reach around the 156 metal plaque. The plate was relocated in the mesh after every bout in order to ensure body repositioning between bouts.

158 Unimanual Reaching: Hanging or in a quadrupedal posture, the animals reached for a raisin 159 or a small piece of papaya, banana or grape placed within view on the floor. Food items were 160 thrown into the cages one at a time and at random positions ensuring complete body repositioning between bouts.

162 The order in which the tasks were tested was: 50 bouts of the Bimanual Big Tube task, 100 163 bouts of the Bimanual Small Tube task, 50 bouts of the Bimanual Big Tube task, 100 bouts of 164 the Unimanual Tube task, 100 bouts of the Unimanual Reaching task. The animals were 165 tested with the next task as soon as they reached the required number of bouts in the previous task. Therefore there was no time lapse between testing on consecutive tasks.

167 In all four tasks, the hand retrieving the food was recorded, together with the body posture 168 that the animal adopted while performing the task (except in the unimanual reaching task 169 which always occurred quadrupedally). Additionally, the finger(s) that was/were inserted into 
170 a tube to retrieve the food was/were recorded using numbers (index: 2, middle: 3, ring: 4,

171 pinky: 5). Combinations were recorded using the numbers of all the digits inserted into a tube

172 (e.g. using the index and middle finger was coded as 23).

173 Body postures were classified as Standing, Sitting or Hanging. Standing required both

174 hindlimbs to be on the floor but not the forelimbs. Sitting was recorded when the buttocks of

175 the animal was touching the floor, and hanging was recorded when three or more limbs were not touching the floor. Only the first hand used and brought to the mouth in a bout of activity was recorded in order to ensure independence of data points (McGrew \& Marchant, 1997).

\section{Data analysis}

180 Data were collected in real time, that is, without video recordings. Individual frequencies and proportions of first hand uses per bout were calculated for each task. Proportions were calculated by dividing the frequencies of left and right hand uses by the total frequency of hand uses recorded per individual. To determine individual hand preferences per task and

184 period, binomial z-scores were calculated to classify the individuals into right hand-preferent 185 ( $\mathrm{z} \geq 1.96)$, left hand-preferent $(\mathrm{z} \leq-1.96)$ or as displaying no hand preference $(-1.96<\mathrm{z}<1.96)$. 186 Binomial tests were used to determine if the differences between left and right proportions of 187 hand use at the individual level were statistically significant. To compare with previous 188 studies, Handedness Index (HI) scores were additionally calculated per individual and task 189 using the formula $(\mathrm{R}-\mathrm{L}) /(\mathrm{R}+\mathrm{L})$ to assess the direction of hand preference, with $\mathrm{R}$ being the 190 number of right hand uses and L being the number of left hand uses. HI values vary between $191-1$ (exclusive use of the left hand) and +1 (exclusive use of the right hand). The HI absolute 192 value (AbsHI) was used to assess the strength of hand preference not considering the 193 direction. 
194 One-sample Wilcoxon tests were used to assess hand preferences at the population level 195 using the HI of each task. Two-tailed paired sample Wilcoxon tests were used to compare i) 196 the individual $\mathrm{HI}$ and AbsHI between the first 50 and the second 50 bouts recorded with the 197 big tube, ii) the individual $\mathrm{HI}$ and AbsHI between tasks, iii) the frequency of each digit 198 combination between pairs of tasks and iv) the individual number of responses performed 199 with a single finger and multiple finger combinations in each tube task. Friedman tests were 200 used to assess if the frequencies of finger use varied as a function of the task and if the 201 strength (AbsHI) and direction (HI) of hand preference varied as a function of the body posture. Two-tailed independent samples Wilcoxon rank sum tests were used to compare the

203 HI and the AbsHI per task between sexes. Effect sizes were calculated using $\mathrm{r}$ scores 204 (Rosenthal et al., 1994; $r=Z / \sqrt{ } N$ ) for paired sample Wilcoxon tests and independent samples Wilcoxon rank sum tests. Kendall's wt coefficient of concordance was used to estimate the effect size for the Friedman tests and Cohen's $d$ was used to estimate the effect sizes in one-sample Wilcoxon tests. Data were analyzed using $\mathrm{R}$ and statistical significance was set at $\mathrm{p}<0.05$.

\section{Results}

\section{Bimanual big tube task}

212 All 14 individuals included in the study showed significant hand preferences in the big tube 213 task (Table 1). Eight individuals significantly preferred the right hand and six individuals 214 significantly preferred the left hand. Thus, as a group the animals did not display a significant 215 hand preference at the population level $(\mathrm{N}=14$, effect size: $\mathrm{d}=0.258, \mathrm{~W}=57.5, \mathrm{P}=0.775)$. The 216 strength $(\mathrm{N}=14$, effect size: $\mathrm{r}=0.456, \mathrm{~W}=7, \mathrm{P}=0.140)$ and direction $(\mathrm{N}=14$, effect size: $\mathrm{r}=$ $2170.831, \mathrm{~W}=7, \mathrm{P}=0.140$ ) of hand preference did not differ significantly between the first and the 218 second 50 bouts of the big tube task. 


\section{Bimanual small tube task}

221 All 14 individuals showed significant hand preferences in the small tube task (Table 2). Nine 222 individuals significantly preferred to use the right hand and five individuals significantly 223 preferred the left hand. Thus, as a group the animals did not display a significant hand 224 preference at the population level $(\mathrm{N}=14$, effect size: $\mathrm{d}=0.138, \mathrm{~W}=63.5, \mathrm{P}=0.504)$. Karen was 225 the only individual that changed the direction of hand preference between the two bimanual 226 tube tasks, showing a significant left-hand preference with the big tube but a significant right227 hand preference with the small tube.

- Table 2 about here -

\section{Unimanual tube task}

230 All 14 individuals showed significant hand preferences in the unimanual tube task. Eight individuals showed a significant right-hand preference and six a significant left-hand 232 preference (Table 3). Thus, as a group the animals did not display a significant hand 233 preference at the population level ( $\mathrm{N}=14$, effect size: $\mathrm{d}=0.139, \mathrm{~W}=55, \mathrm{P}=0.899)$.

- Table 3 about here -

\section{Unimanual Reaching task}

236 Thirteen out of 14 individuals showed a significant hand preference in the unimanual 237 reaching task (Table 4). Seven individuals showed a significant right-hand preference and six 238 a significant left-hand preference. Thus, as a group the animals did not display a significant 239 hand preference at the population level ( $N=14$, effect size: $\mathrm{d}=0.042, \mathrm{~W}=38, \mathrm{P}=0.6246)$.

241 All analyses were repeated excluding Karen as some fingers of her left hand were disabled, 242 probably due to improperly healed broken digits. However the results regarding hand 243 preference at the population level did not differ from when Karen was included in the 
244 analysis $(\mathrm{N}=13$, bimanual small tube: effect size: $\mathrm{d}=0.204, \mathrm{~W}=53.5, \mathrm{P}=0.594$; bimanual big

245 tube: effect size: $d=0.185, W=51.5, P=0.697$; unimanual tube: effect size: $d=0.217, W=48$,

$246 \mathrm{P}=0.888$; unimanual reaching: effect size: $\mathrm{d}=0.044, \mathrm{~W}=38, \mathrm{P}=0.625)$.

- Table 4 about here -

\section{Comparison between tasks}

249 The direction of hand preference did not differ significantly between any of the four tasks

250 (big tube versus small tube: $\mathrm{N}=14$, effect size: $\mathrm{r}=0.3324, \mathrm{~W}=16, \mathrm{P}=0.261$; big tube versus

251 unimanual tube: $\mathrm{N}=14$, effect size: $\mathrm{r}=0.103, \mathrm{~W}=19, \mathrm{P}=0.722$; big tube versus unimanual 252 reaching: $\mathrm{N}=14$, effect size: $\mathrm{r}=0.151, \mathrm{~W}=54, \mathrm{P}=0.576$; small tube versus unimanual tube: $\mathrm{N}=$ 253 14, effect size: $r=0.060, \mathrm{~W}=23.5, \mathrm{P}=0.953$; small tube versus unimanual reaching: $\mathrm{N}=14$, 254 effect size: $\mathrm{r}=0.352, \mathrm{~W}=65, \mathrm{P}=0.184$; unimanual tube versus unimanual reaching: $\mathrm{N}=14$, 255 effect size: $\mathrm{r}=0.260, \mathrm{~W}=59.5, \mathrm{P}=0.345$ ) (Figure 1, left panel).

256 The strength of hand preference, however, differed significantly between tasks: it was 257 significantly lower in the unimanual reaching task compared to all three tube tasks 258 (unimanual reaching versus unimanual tube: $\mathrm{N}=14$, effect size: $\mathrm{r}=0.839, \mathrm{~W}=90, \mathrm{P}=0.002$; 259 unimanual reaching versus bimanual small tube: $\mathrm{N}=14$, effect size: $\mathrm{r}=0.654, \mathrm{~W}=80, \mathrm{P}=0.018$; 260 unimanual reaching versus bimanual big tube: $\mathrm{N}=14$, effect size: $\mathrm{r}=0.621, \mathrm{~W}=78, \mathrm{P}=0.025$ ).

261 In contrast, no significant differences in the strength of hand preference were found between 262 the three tube tasks (unimanual tube versus bimanual small tube: $\mathrm{N}=14$, effect size: $\mathrm{r}=0.060$, $263 \mathrm{~W}=23.5, \mathrm{P}=0.953$; unimanual tube versus bimanual big tube: $\mathrm{N}=14, \mathrm{~W}=21$, effect size: $264 \mathrm{r}=0.017, \mathrm{P}=0.906$; bimanual small tube versus bimanual big tube: $\mathrm{N}=14$, effect size: $\mathrm{r}=0.138$, $265 \mathrm{~W}=17, \mathrm{P}=0.552$ ) (Figure 1, right panel).

266 When the analysis was repeated without Karen, the results did not differ. 
269 Regarding the consistency of hand preference (Table 5), ten of the 14 individuals were 270 completely consistent in the direction of hand preference. Four individuals were only 271 partially consistent. Among those, three individuals (Chavela, Margarita, Neri) were 272 consistent in the direction of hand preference in the three tube tasks, but showed a significant 273 hand preference for the other hand in the unimanual reaching task. One individual (Karen) 274 displayed a left-hand preference in two of the tasks, a right-hand preference in one task, and 275 an ambidexterity in the remaining task (see Table 5).

\section{Finger use comparisons}

278 The spider monkeys used one, two, three or all four fingers to retrieve the food from the 279 inside of the tubes. A total of ten combinations of single or multiple finger uses were observed. In the bimanual tasks, three-finger combinations (234 and 345) only occurred with the big tube, with 234 being much more frequent (145 uses) than 345 (8 uses). The fourfinger combination 2345 only occurred once with the big tube. One- and two-finger use combinations occurred with both the big and the small tube. However, only four of these finger combinations were present in both tasks (2, 3, 4 and 23). The finger combinations 34, 285 45 and 24 only occurred with the big tube task.

The index finger was the most commonly used single finger in the big tube task $(51 \%$ of the bouts) as well as in the small tube task (69\%). The most common finger combination in the big tube task (18\%) was the index and the middle finger (23), and this was also the only combination that was observed in the small tube task. In the big tube task, single fingers were used in a total of 709 bouts (53\%), while combinations of more than one finger were used in 640 bouts (47\%), although this difference was not significant $(N=14$, effect size: $r=0.125$, $\mathrm{W}=57, \mathrm{P}=0.802)$. In the small tube task, single finger uses occurred in 1399 bouts $(99.9 \%)$ and combinations of more than one finger only occurred once $(0.01 \%)$. Single fingers were 
294 thus used significantly more often than multiple fingers combined in the small tube task $(\mathrm{N}=$ 295 14, effect size: $\mathrm{r}=0.972, \mathrm{~W}=105, \mathrm{P}=0.0003$ ). The index finger (2) and the middle finger (3) 296 were used significantly more often in the small than in the big tube task (index: $\mathrm{N}=14$, effect 297 size: $\mathrm{r}=0.837, \mathrm{~W}=0, \mathrm{P}=0.004$; middle: $\mathrm{N}=14$, effect size: $\mathrm{r}=0.616, \mathrm{~W}=1, \mathrm{P}=0.021)$. However, 298 the combination of index and middle fingers (23) was used significantly more often in the big 299 tube than in the small tube task ( $\mathrm{N}=14$, effect size: $\mathrm{r}=0.859, \mathrm{~W}=78, \mathrm{P}=0.002)$.

300 Regarding the unimanual tube task, eight combinations of single and multiple finger uses 301 were observed. However, the combination of index and ring finger (24) was not used in this 302 task, whereas the combination of ring and pinky finger (45) was used in one occasion exclusively on this task. Again, the index finger (2) was the most commonly used one (48\%). Single fingers were used in 688 bouts (49\%) whereas multiple-finger combinations were used 305 in 712 bouts (51\%), although this difference was not significant $(N=14$, effect size: $r=0.143$, $\mathrm{W}=61, \mathrm{P}=0.615)$. No significant differences were found in the number of finger uses between the unimanual and the big tube task. However, significant differences were found between 308 the unimanual and the small tube task regarding the use of the index $(\mathrm{N}=14$, effect size: $309 \mathrm{r}=0.685, \mathrm{~W}=6, \mathrm{P}=0.0418)$, middle $(\mathrm{N}=14$, effect size: $\mathrm{r}=0.695, \mathrm{~W}=0, \mathrm{P}=0.022)$, and combination of index and middle fingers ( $\mathrm{N}=14$, effect size: $\mathrm{r}=0.837, \mathrm{~W}=66, \mathrm{P}=0.004)$ were used.

312 A comparison between the three tube tasks (Figure 2) showed that the type of task 313 significantly affected the number of bouts where the index $(\mathrm{N}=14$, effect size: $\mathrm{wt}=0.486$ $\left.314 \chi^{2}=13.682, \mathrm{P}=0.001\right)$, middle $\left(\mathrm{N}=14\right.$, effect size: $\left.\mathrm{wt}=0.192, \chi^{2}=8.194, \mathrm{P}=0.017\right)$, ring $(\mathrm{N}=14$, 315 effect size: $\mathrm{wt}=0.256, \chi^{2}=8.824, \mathrm{P}=0.012$ ) and the combination of index and middle finger $316 \quad\left(\mathrm{~N}=14\right.$, effect size: $\left.\mathrm{wt}=0.246, \chi^{2}=18.136, \mathrm{P}<0.001\right)$ were used.

317 When the analysis was repeated without Karen, the results did not differ. 
- Figure 2 about here -

320

321

\section{Relation between posture and hand use}

When solving the bimanual tube tasks, in $47 \%$ of the bouts the individuals were hanging, in $44 \%$ of the bouts they were sitting and in $9 \%$ they were standing. In the case of those individuals which did not use the same hand in $95 \%$ or more of the bouts, hand preference did not differ significantly as a function of body posture neither when using the big tube nor the small tube. The direction and strength of hand preference did not significantly differ as a function of body posture in the big tube task $(\mathrm{N}=13$; direction $(\mathrm{HI})$ : effect size: $\mathrm{wt}=0.329$, $\mathrm{df}=2, \chi^{2}=0.07, \mathrm{P}=0.96$; strength (AbsHI): effect size: $\mathrm{wt}=0.284, \mathrm{df}=2, \chi^{2}=0.67, \mathrm{P}=0.72$ ) or the small tube task $\left(\mathrm{N}=11\right.$; direction $(\mathrm{HI})$ : effect size: $\mathrm{wt}=0.31, \mathrm{df}=2, \chi^{2}=1.09, \mathrm{P}=0.58$; strength (AbsHI): effect size: $\mathrm{wt}=0.326, \mathrm{df}=2, \chi^{2}=3.27, \mathrm{P}=0.19$ ). However, pairwise comparisons using Canover's test showed that the strength of hand preference differed significantly between the sitting and the standing postures in the small tube task $(\mathrm{P}=0.007)$.

When solving the unimanual tube task, in $45 \%$ of the bouts the individuals were hanging, in $39 \%$ they were sitting and in $16 \%$ the individuals were standing. Again, in the case of those individuals that did not use the same hand in $95 \%$ or more of the bouts, hand preference did not differ significantly as a function of body posture. The direction ( $\mathrm{N}=9$, effect size: $\left.\mathrm{wt}=0.431, \mathrm{df}=2, \chi^{2}=2.29, \mathrm{P}=0.32\right)$ and strength $\left(\mathrm{N}=9\right.$, effect size: $\mathrm{wt}=0.384, \mathrm{df}=2, \chi^{2}=2.29$, $\mathrm{P}=0.32$ ) of hand preference did not differ as a function of body posture in the unimanual tube task.

\section{Comparisons between males and females}

No significant differences in hand use between sexes were found in any of the four tasks regarding direction of hand preference (big tube: $\mathrm{Nf}=7, \mathrm{Nm}=7$, effect size: $\mathrm{r}=0.052, \mathrm{~W}=23$, $\mathrm{P}=0.90$; small tube: $\mathrm{Nf}=7, \mathrm{Nm}=7$, effect size: $\mathrm{r}=0, \mathrm{~W}=24.5, \mathrm{P}=1$; unimanual tube: $\mathrm{Nf}=7$, 
$344 \mathrm{Nm}=7$, effect size: $\mathrm{r}=0.104, \mathrm{~W}=21.5, \mathrm{P}=0.75$; unimanual reaching $\mathrm{Nf}=7, \mathrm{Nm}=7$, effect size: $345 \mathrm{r}=0.308, \mathrm{~W}=15.5, \mathrm{P}=0.28$ ) or strength of hand preference (big tube: $\mathrm{Nf}=7, \mathrm{Nm}=7$, effect size: $346 \mathrm{r}=-0.054, \mathrm{~W}=26, \mathrm{P}=0.89$; small tube: $\mathrm{Nf}=7, \mathrm{Nm}=7$, effect size: $\mathrm{r}=-0.439, \mathrm{~W}=36.5, \mathrm{P}=0.12$; 347 unimanual tube: $\mathrm{Nf}=7, \mathrm{Nm}=7$, effect size: $\mathrm{r}=-0.320, \mathrm{~W}=33.5, \mathrm{P}=0.26$; unimanual reaching: $348 \mathrm{Nf}=7, \mathrm{Nm}=7$, effect size: $\mathrm{r}=-0.239, \mathrm{~W}=31.5, \mathrm{P}=0.41)$.

\section{Discussion}

351 The results of the present study demonstrate that black-handed spider monkeys display 352 significant hand preferences at the individual, but not at the population level. This was true 353 both in two bimanual coordination tasks and in two unimanual tasks. Further, our results 354 show that the majority of animals was consistent in the hand they preferred in these four 355 tasks.

\section{Comparison between tasks}

358 Although it is often difficult to properly define whether motor tasks differ in their task 359 demands, it seems plausible to assume that the four tasks employed in the present study 360 clearly differ in this respect: the unimanual tube task can be considered as more demanding than the unimanual reaching task as it required an animal to insert its finger(s) into the tube

362 which necessitates the use of individual fingers rather than a simple power grip plus a higher 363 degree of motor precision than simple food retrieval from a flat surface. Similarly, both 364 bimanual tube tasks can be considered as more demanding than the two unimanual tasks as they required an animal to coordinate the motor actions of both hands and prevented it from using one hand for postural support whereas the two unimanual tasks did not. Finally, the

367 small tube task can be considered as more demanding than the big tube task as it required an 
368 animal to insert its finger(s) into a smaller tube opening which necessitates a higher degree of

369 motor precision compared to a wider tube opening.

370 Several studies reported a positive correlation between the degree of task demand and the 371 strength of hand preference that nonhuman primates display (e.g. Fagot \& Vauclair, 1991;

372 Meunier \& Vauclair, 2007; Hook \& Rogers, 2008; Lilak \& Phillips, 2008). Our findings only

373 partially support this notion: whereas the strength of hand preference was significantly higher 374 in the three tube tasks compared to the simple unimanual reaching task (see Figure 1), no 375 significant differences were found in the absolute HI scores between the three tube tasks. 376 Three explanations, which are not mutually exclusive, might account for this finding: firstly, 377 a ceiling effect may have prevented more clear-cut differences in the strength of hand 378 preferences between tasks. This notion is supported by our finding that, with only few 379 exceptions, all absolute HI scores in the three tube tasks were $\geq 0.80$ (see Tables 1 , 2, and 3), 380 leaving only little room for between-task differences. Secondly, the effects of presence or 381 absence of postural support (in the unimanual versus bimanual tube tasks) and of the 382 difference in motor precision required (in the big versus small tube task) which have been 383 reported in other studies (e.g. Canteloup et al., 2013; Nelson \& Boeving, 2015) may not have 384 been big enough for the spider monkeys to have a significant impact on the strength of hand preference. In this context, it should also be mentioned that success rate, another measure of task demand, was $100 \%$ in all three tube tasks, meaning that the spider monkeys always 387 succeeded in retrieving the food from the tubes. Thirdly, there could have been a carryover 388 effect as testing the two bimanual tasks before testing the unimanual task may have affected the performance in the latter. In our view this last possibility is unlikely as we failed to find evidence that performing a more complex task (bimanual small tube task) had a significant

391 effect on the direction or strength of hand preference in a less complex task (bimanual big 392 tube task). Nevertheless, we cannot exclude the possibility that the combined effect of testing 
393 both bimanual tasks before, may have elicited stronger hand preferences in the unimanual

394 task. Therefore, we suggest that future studies should perform tasks in both ascending and 395 descending order of complexity for specifically assessing the above-mentioned carryover 396 effect.

397 It is interesting to note that even the least demanding one of the four tasks assessed here, 398 unimanual reaching for food from a flat surface, elicited significant hand preferences in all 399 but one of the spider monkeys. This is in contrast to findings from several other species of 400 nonhuman primates which reported a lack of significant hand preferences at the individual 401 level for this motor pattern in at least some, or even in the majority of the studied animals 402 (e.g. squirrel monkeys: Laska, 1996b; capuchin monkeys: Lilak \& Phillips, 2008; Tonkean 403 macaques: Canteloup et al., 2013; Barbary macaques: Schmitt et al., 2008; Olive baboons: 404 Vauclair et al., 2005 but see Hook \& Rogers, 2000 in common marmosets). The fact that 405 spider monkeys are lacking a thumb might explain this discrepancy as it makes grasping of small food items more difficult for members of the genus Ateles than for primates having a

407 thumb. This notion is supported by the finding that spider monkeys prefer to use their mouth 408 rather than a hand for retrieving food from the ground when they have the opportunity to 409 choose between these two options (Laska, 1996a).

\section{Comparison with other tube task studies}

412 Our finding that black-handed spider monkeys display significant hand preferences at the 413 individual level, but not at the population level is in line with the majority of studies that 414 employed the tube task with other species (e.g. rhesus macaques: Bennett et al., 2008; 415 Tonkean macaques: Canteloup et al., 2013; capuchin monkeys: Lilak \& Phillips, 2008; 416 squirrel monkeys: Meguerditchian et al., 2012; De Brazza’s monkeys and red-capped 417 mangabeys: Maille et al., 2013). Another member of the genus Ateles, the Colombian spider 
418 monkey (Ateles fusciceps rufiventris) has also been found to only display significant hand

419 preferences at the individual level in this bimanual coordination task (Nelson \& Boeving,

420 2015). Studies that reported population-level hand preferences in the tube task are so far

421 mainly restricted to the Great Apes (chimpanzees, bonobos, gorillas, and orangutans:

422 Hopkins et al., 2011) and the Lesser Apes (siamangs and white-cheeked gibbons: Morino et

423 al., 2017). Whether this reflects a phylogenetic difference between hominoid and non-

424 hominoid primates or is perhaps due to the large sample sizes employed in the studies with

425 hominoids remains an open question.

426 The few studies so far which tested other species of nonhuman primates with both a big and a

427 small tube or with a unimanual and a bimanual version of the tube task yielded mixed results:

428 whereas Canteloup et al. (2013) - in line with our findings - found no significant difference

429 in the strength of hand preference as a function of tube diameter in Tonkean macaques

430 (Macaca tonkeana), Nelson and Boeving (2015) did find such a difference in Colombian

431 spider monkeys (Ateles fusciceps rufiventris). Maille et al. (2013) reported that the strength of

432 hand preference in De Brazza's monkeys (Cercopithecus neglectus) and red-capped

433 mangabeys (Cercopithecus torquatus) was significantly higher in the bimanual than in the

434 unimanual version of the tube task. Future studies including primate species which have not

435 been tested so far with different versions of the tube task might help to elucidate which

436 factors may account for such between-species differences.

437

438 Consistency of hand preference across tasks

439 We found that the majority of animals of the present study were consistent in the hand they

440 preferred across all four tasks (Table 5). Due to their basic similarity, it may not seem too

441 surprising that the three versions of the tube task employed here elicited consistent hand

442 preferences. Accordingly, Tonkean macaques (Canteloup et al., 2013) and Colombian spider 
443 monkeys (Nelson \& Boeving, 2015) have also been reported to be consistent in their

444 preferred hand when tested with a small and a wide tube, respectively, and De Brazza's 445 monkeys and red-capped mangabeys (Maille et al., 2013) were consistent in the hand they 446 preferred when tested with a unimanual and a bimanual version of the tube task.

447 It is interesting to note, however, that ten out of 14 of our animals were also consistent in 448 their preferred hand when comparing between the three tube tasks and simple unimanual 449 reaching. This is in line with findings from Colombian spider monkeys (Nelson et al., 2015) 450 which are closely related to our study species, but in contrast with several other studies which 451 reported that only a minority of animals were consistent in these two tasks (Tonkean 452 macaques: Canteloup et al., 2013; capuchin monkeys: Lilak \& Phillips, 2008; squirrel 453 monkeys, Meguerditchian et al., 2012; rhesus macaques: Nelson et al., 2011; De Brazza’s 454 monkeys: Schweitzer et al., 2007).

455 Our finding of consistency in preferential hand use not only across similar tasks, but also 456 across dissimilar ones, raises the question whether black-handed spider monkeys may qualify 457 as displaying manual specialization which has been defined by McGrew and Marchant 458 (1997) as individuals being consistent in their preferred hand across a range of manual tasks. 459 There is no consensus with regard to how many manual tasks should be included and how 460 different these tasks should be in order to assign individual animals as being manually 461 specialized. We feel that four tasks - as assessed in the present study - are definitely not 462 sufficient for assigning such a label, particularly when considering that three of our tasks 463 involved food retrieval from a tube, and thus basically similar tasks.

464 In this context, it should also be mentioned that a lack of consistency in hand use across tasks 465 may simply reflect that the integrity of one of the hands of an animal may be compromised.

466 Injuries such as broken digits or wrists are frequent in arboreal primates such as spider 467 monkeys and often lead to permanent impairment of the affected hand (Arlet et al., 2009). 
468 This notion fits to at least one of the animals of the present study which was not consistent in 469 her preferred hand: Karen had some fingers of the left hand disabled, probably due to 470 improperly healed broken digits, which made the hand functional for the tasks with the big 471 tube but required the use of the other hand with the small tube. Nevertheless, Karen used both 472 hands and different finger combinations (8 in total including both hands), and displayed hand 473 preferences and finger use preferences, which qualify her for being included in this study. 474 Furthermore, when we repeated the statistical analysis excluding Karen's data we obtained 475 the same significant results in the same tests as when her data were included.

476

\section{Finger use in the tube tasks}

478 We found that the index finger was the most-frequently used digit in all three tube tasks 479 (Figure 2). This is in line with all previous studies which assessed finger use in the tube task 480 with other species of primates (chimpanzees: Llorente et al., 2009; capuchin monkeys: Meunier \& Vauclair, 2007; De Brazza’s monkeys and red-capped mangabeys: Maille et al., 482 2013; rhesus macaques: Westergaard \& Suomi, 1996; Olive baboons: Vauclair et al., 2005; 483 Colombian spider monkeys: Nelson \& Boeving, 2015). Considering that spider monkeys are rather limited in the independent motor control of their fingers (Fragaszy \& Crast, 2016), this is remarkable as it demonstrates that the restricted manual dexterity of Ateles geoffroyi nevertheless allows for the deliberate use of single digits. Another platyrrhine primate, the 487 squirrel monkey, has been found unable to insert a single digit into a narrow tube when 488 performing the tube task, and to use the whole hand when the tube's diameter allowed for this option (Meguerditchian et al., 2012). Capuchin monkeys, in contrast, have been shown to display fine motor control of individual fingers in a variety of tasks (Christel \& Fragaszy, 4912000 ) including the tube task (Westergaard \& Suomi, 1996). This suggests that the degree of 
492 independent motor control of fingers differs considerably among platyrrhine primates, with

493 spider monkeys falling between squirrel monkeys and capuchin monkeys.

494 However, the spider monkeys of the present study also used digits other than the index finger,

495 either alone or in combination, in a considerable proportion of bouts. Not surprisingly, the

496 use of two- or three-finger combinations occurred much more often with the big tube

497 compared to the small tube (Figure 2), suggesting that the animals used multiple-finger

498 combinations to increase their efficiency in retrieving the food from the inside of the tube.

499 Although it was not the aim of the present study to collect data on the independence of motor

500 control of individual fingers, we did observe variation in this regard. Some individuals bent

501 the fingers when retrieving food from the tube with one finger while others kept all fingers

502 extended in parallel and oriented the hand so that only one finger was introduced into the

503 tube. We suggest that future studies should conduct systematic observations of individual

504 finger motor control in order to determine if the variation observed is accounted for by

505 individual differences in finger dexterity or if, alternatively, it is the consequence of

506 particular finger or fingers used to retrieve food in the tube task.

507

508 Hand preference as a function of sex and body posture

509 Our finding of a lack of sex differences in both direction and strength of hand preferences in

510 the black-handed spider monkey is in line with the majority of studies that employed the tube

511 task (chimpanzees, bonobos, gorillas, and orangutans: Hopkins et al., 2011; capuchin

512 monkeys: Lilak \& Phillips, 2008; De Brazza’s monkeys and red-capped mangabeys: Maille

513 et al., 2013; squirrel monkeys: Meguerditchian et al., 2012; Barbary macaques: Schmitt et al.,

514 2008; Olive baboons: Vauclair et al., 2005; Colombian spider monkeys: Nelson et al., 2015).

515 However, Bennett et al. (2008) reported that female rhesus macaques displayed significantly

516 stronger hand preferences in the tube task compared to males. A previous study on hand 
517 preferences in black-handed spider monkeys which assessed visually- and tactually-guided

518 food reaching tasks also failed to find any sex differences in our study species (Laska, 519 1996a).

520 Similarly, we found no effect of body posture on the direction or strength of hand preferences 521 in our study population, although we did find significant differences in the strength of hand 522 preference in the most demanding tube task (Binomial small tube task) between the standing 523 and hanging postures. Whereas several studies reported that body posture can significantly 524 affect preferential hand use in a variety of tasks (e.g. Laska, 1996b; McGrew \& Marchant, 525 1997; Cashmore et al., 2008; Hook \& Rogers, 2008; Braccini et al., 2010), the few studies so 526 far that considered body posture as a possible variable in the tube task failed to find any 527 effects on both direction and strength of hand preferences (De Brazza's monkeys and red528 capped mangabeys: Maille et al., 2013; capuchin monkeys: Spinozzi et al., 1998). 529 Nevertheless, and considering our results, we suggest that future studies on hand preferences 530 employing the tube task should systematically vary body posture and assess its possible 531 effects on preferential hand use.

532

533 In summary, we conclude that limited manual dexterity does not prevent spider monkeys 534 from displaying strong and consistent hand preferences at the individual level.

\section{References}

537 Ankel-Simons, F. (2007). Primate Anatomy: an introduction. Amsterdam: Elsevier.

538 Arlet, M. E., Carey , J. R., \& Molleman, F. (2009). Species, age and sex differences in type 539 and frequencies of injuries and impairments among four arboreal primate species in $540 \quad$ Kibale National Park, Uganda. Primates, 50, 65-73. 
541 Braccini, S., Lambeth, S., Schapiro, S., \& Fitch, W. T. (2010). Bipedal tool use strengthens chimpanzee hand preferences. Journal of Human Evolution, 58, 234-241.

543 Canteloup, C., Vauclair, J., \& Meunier, H. (2013). Hand preferences on unimanual and bimanual tasks in Tonkean macaques (Macaca tonkeana). American Journal of Physical Anthropology, 152, 315-321.

Cashmore, L., Uomini, N., \& Chapelain, A. (2008). The evolution of handedness in humans and great apes: a review and current issues. Journal of Anthropological Sciences, 86, 735.

Christel, M. I., \& Fragaszy, D. (2000). Manual function in Cebus apella. Digital mobility, preshaping, and endurance in repetitive grasping. International Journal of Primatology, 21, 697-719.

Fagot, J., \& Vauclair, J. (1991). Manual laterality in nonhuman primates: a distinction between handedness and manual specialization. Psychological Bulletin, 109, 76-89.

Fragaszy, D. M., \& Crast, J. (2016). Functions of the hand in primates. In: T. L. Kivell, P. Lemelin, B. G. Richmond, \& D. Schmitt (Eds.) The evolution of the primate hand (pp. 313-344). New York: Springer.

Hook, M. A., \& Rogers, L. J. (2000) Development of hand preferences in marmosets (Callithrix jacchus) and effects of ageing. Journal of Comparative Psychology, 114,

560 Hook, M. A., \& Rogers, L. J. (2008) Visuospatial reaching preferences of common marmosets: An assessment of individual biases across a variety of tasks. Journal of Comparative Psychology, 122, 41-51.

Hopkins, W. D., Misiura, M., Pope, S. M., \& Latash, E. M. (2015). Behavioral and brain asymmetries in primates: a preliminary evaluation of two evolutionary hypotheses. Annals of the New York Academy of Sciences, 1359, 65-83. 
566 Hopkins, W. D., Phillips, K. A., Bania, A., Calcutt, S. E., Gardner, G., Russell, J., Schaeffer, 567 J., Lonsdorf, E. V., Ross, S. R., \& Schapiro, S. J. (2011). Hand preferences for 568 coordinated bimanual actions in 777 great apes: implications for the evolution of handedness in Hominins. Journal of Human Evolution, 60, 605-611.

570 Laska, M. (1996a). Manual laterality in spider monkeys (Ateles geoffroyi) solving visually and tactually guided food-reaching tasks. Cortex, 32, 717-726.

Laska, M. (1996b). A study of correlates of hand preferences in squirrel monkeys (Saimiri sciureus). Primates, 37, 457-465.

Lilak, A. L., \& Phillips, K. A. (2008). Consistency of hand preference across low-level and high-level tasks in capuchin monkeys (Cebus apella). American Journal of Primatology, 70 , 254-260.

Llorente, M., Mosquera, M., \& Fabré, M. (2009). Manual laterality for simple reaching and bimanual coordinated task in naturalistic housed Pan troglodytes. International Journal of Primatology, 30, 183-197.

Maille, A., Belbeoc’h, C., Rossard, A., Bec, P., \& Blois-Heulin, C. (2013). Which are the 581 features of the TUBE task that make it so efficient in detecting manual asymmetries? An investigation in two cercopithecine species (Cercopithecus neglectus and

McGrew, W. C., \& Marchant, L. F. (1997). On the other hand: current issues and metaanalysis of the behavioral laterality of hand function in nonhuman primates. Yearbook of Physical Anthropology, 40, 201-232.

Meguerditchian, A., Donnot, J., Molesti, S., Francioly, R., \& Vauclair, J. (2012). Sex 588 difference in squirrel monkeys' handedness for unimanual and bimanual coordinated tasks. Animal Behaviour, 83, 635-643. 
590 Meguerditchian, A., Vauclair, J., \& Hopkins, W. D. (2013). On the origins of human 591 handedness and language: a comparative review of hand preferences for bimanual coordinated actions and gestural communication in nonhuman primates. Developmental Psychobiology, 55, 637-650.

594 Meunier, H., \& Vauclair, J. (2007). Hand preferences on unimanual and bimanual tasks in 595 white-faced capuchins (Cebus capucinus). American Journal of Primatology, 69, 1064596 1069.

Morino, L., Uchikoshi, M., Bercovitch, F., Hopkins, W. D., \& Matsuzawa, T. (2017). Tube 598 task hand preference in captive hylobatids. Primates, 58, 403-412.

599 Nelson, E. L., \& Boeving, E. R. (2015). Precise digit use increases the expression of 600 handedness in Colombian spider monkeys (Ateles fusciceps rufiventris). American 601 Journal of Primatology, 77, 1253-1262.

602

Nelson, E. L., Figueroa, A., Albright, S. N., \& Gonzalez, M. F. (2015). Evaluating 603 handedness measures in spider monkeys. Animal Cognition, 18, 345-353.

604 Rosenthal, R., Cooper, H., \& Hedges, L. V. (1994). Parametric measures of effect size. In: H. 605 Cooper, L. V. Hedges (Eds.) The handbook of research synthesis (pp. 231-244). New 606 York: Russell Sage Foundation.

607 Schmitt, V., Melchisedech, S., Hammerschmidt, K., \& Fischer, J. (2008) Hand preferences in 608

609 Spinozzi, G., Castorina, M. G., \& Truppa, V. (1998). Hand preferences in unimanual and 610 coordinated-bimanual tasks by tufted capuchins (Cebus apella). Journal of Comparative Psychology, 112, 183-191.

612 Vauclair, J., Meguerditchian, A., \& Hopkins, W. D. (2005). Hand preferences for unimanual 613 and coordinated bimanual tasks in baboons (Papio anubis). Cognitive Brain Research, 25, 201-216. 
615 Westergaard, G. C., \& Suomi, S. J. (1996). Hand preference for a bimanual task in tufted 616 capuchins (Cebus apella) and rhesus macaques (Macaca mulatta). Journal of 617 Comparative Psychology, 110, 406-411. 
618 Table 1

619 Individual hand use frequencies, HI scores, AbsHI scores, and binomial Z-scores in the 620 bimanual big tube task

\begin{tabular}{lllllll}
\hline & $\mathrm{L}$ & $\mathrm{R}$ & $\mathrm{HI}$ & AbsHI & Z-scores & P value \\
\hline Brutus & 1 & 99 & 0.98 & 0.98 & 9.7 & $<<0.001$ \\
Cejitas & 100 & 0 & -1.00 & 1.00 & -10.1 & $<<0.001$ \\
Colin & 0 & 100 & 1.00 & 1.00 & 9.9 & $<<0.001$ \\
Edgar & 100 & 0 & -1.00 & 1.00 & -10.1 & $<<0.001$ \\
Frida & 0 & 100 & 1.00 & 1.00 & 9.9 & $<<0.001$ \\
Karen & 92 & 8 & -0.84 & 0.84 & -8.5 & $<<0.001$ \\
Kelly & 6 & 94 & 0.88 & 0.88 & 8.7 & $<<0.001$ \\
Lucas & 6 & 94 & 0.88 & 0.88 & 8.7 & $<<0.001$ \\
Mari & 29 & 71 & 0.42 & 0.42 & 4.1 & $<<0.001$ \\
Paulina & 100 & 0 & -1.00 & 1.00 & -10.1 & $<<0.001$ \\
Chavela & 94 & 6 & -0.88 & 0.88 & -8.9 & $<<0.001$ \\
Margarita & 0 & 100 & 1.00 & 1.00 & 9.9 & $<<0.001$ \\
Neri & 10 & 90 & 0.80 & 0.80 & 7.9 & $<<0.001$ \\
Yayo & 92 & 8 & -0.84 & 0.84 & -8.5 & $<<0.001$
\end{tabular}

621 Note. L: Left-hand use. R: Right-hand use. HI: Handedness Index.

622 AbsHI: absolute value of the HI.

623 
624 Table 2

625 Individual hand use frequencies, HI scores, AbsHI scores, and binomial Z-scores in the 626 bimanual small tube task

\begin{tabular}{lllllll}
\hline & $\mathrm{L}$ & $\mathrm{R}$ & $\mathrm{HI}$ & AbsHI & Z-scores & P value \\
\hline Brutus & 0 & 100 & 1.00 & 1.00 & 9.9 & $<<0.001$ \\
Cejitas & 100 & 0 & -1.00 & 1.00 & -10.1 & $<<0.001$ \\
Colin & 0 & 100 & 1.00 & 1.00 & 9.9 & $<<0.001$ \\
Edgar & 99 & 1 & -0.98 & 0.98 & -9.9 & $<<0.001$ \\
Frida & 0 & 100 & 1.00 & 1.00 & 9.9 & $<<0.001$ \\
Karen & 8 & 92 & 0.84 & 0.84 & 8.3 & $<<0.001$ \\
Kelly & 8 & 92 & 0.84 & 0.84 & 8.3 & $<<0.001$ \\
Lucas & 0 & 100 & 1.00 & 1.00 & 9.9 & $<<0.001$ \\
Mari & 18 & 82 & 0.64 & 0.64 & 6.3 & $<<0.001$ \\
Paulina & 100 & 0 & -1.00 & 1.00 & -10.1 & $<<0.001$ \\
Chavela & 89 & 11 & -0.78 & 0.78 & -7.9 & $<<0.001$ \\
Margarita & 1 & 99 & 0.98 & 0.98 & 9.7 & $<<0.001$ \\
Neri & 9 & 91 & 0.82 & 0.82 & 8.1 & $<<0.001$ \\
Yayo & 100 & 0 & -1.00 & 1.00 & -10.1 & $<<0.001$
\end{tabular}

627 Note. L: Left-hand use. R: Right-hand use. HI: Handedness Index.

628 AbsHI: absolute value of the HI. 
629 Table 3

630 Individual hand use frequencies, HI scores, AbsHI scores, and binomial Z-scores in the 631 unimanual tube task

\begin{tabular}{lllllll}
\hline & $\mathrm{L}$ & $\mathrm{R}$ & $\mathrm{HI}$ & AbsHI & Z-scores & P value \\
\hline Brutus & 5 & 95 & 0.90 & 0.90 & 8.9 & $<<0.001$ \\
Cejitas & 100 & 0 & -1.00 & 1.00 & -10.1 & $<<0.001$ \\
Colin & 0 & 100 & 1.00 & 1.00 & 9.9 & $<<0.001$ \\
Edgar & 100 & 0 & -1.00 & 1.00 & -10.1 & $<<0.001$ \\
Frida & 0 & 100 & 1.00 & 1.00 & 9.9 & $<<0.001$ \\
Karen & 91 & 9 & -0.82 & 0.82 & -8.3 & $<<0.001$ \\
Kelly & 4 & 96 & 0.92 & 0.92 & 9.1 & $<<0.001$ \\
Lucas & 10 & 90 & 0.80 & 0.80 & 7.9 & $<<0.001$ \\
Mari & 6 & 94 & 0.88 & 0.88 & 8.7 & $<<0.001$ \\
Paulina & 100 & 0 & -1.00 & 1.00 & -10.1 & $<<0.001$ \\
Chavela & 84 & 16 & -0.68 & 0.68 & -6.9 & $<<0.001$ \\
Margarita & 5 & 95 & 0.90 & 0.90 & 8.9 & $<<0.001$ \\
Neri & 3 & 97 & 0.94 & 0.94 & 9.3 & $<<0.001$ \\
Yayo & 100 & 0 & -1.00 & 1.00 & -10.1 & $<<0.001$ \\
\hline
\end{tabular}

632 Note. L: Left-hand use. R: Right-hand use. HI: Handedness Index.

633 AbsHI: absolute value of the HI. 
634 Table 4

635 Individual hand use frequencies, HI scores, AbsHI scores, and binomial Z-scores in the 636 unimanual reaching task

\begin{tabular}{lcccccc}
\hline & $\mathrm{L}$ & $\mathrm{R}$ & $\mathrm{HI}$ & AbsHI & Z-scores & P value \\
\hline Brutus & 34 & 66 & 0.32 & 0.32 & 3.1 & 0.002 \\
Cejitas & 100 & 0 & -1.00 & 1.00 & -10.1 & $<<0.001$ \\
Colin & 6 & 94 & 0.88 & 0.88 & 8.7 & $<<0.001$ \\
Edgar & 96 & 4 & -0.92 & 0.92 & -9.3 & $<<0.001$ \\
Frida & 14 & 86 & 0.72 & 0.72 & 7.1 & $<<0.001$ \\
Karen & 50 & 50 & 0.00 & 0.00 & -0.1 & 1.000 \\
Kelly & 12 & 88 & 0.76 & 0.76 & 7.5 & $<<0.001$ \\
Lucas & 32 & 68 & 0.36 & 0.36 & 3.5 & $<<0.001$ \\
Mari & 10 & 90 & 0.80 & 0.08 & 7.9 & $<<0.001$ \\
Paulina & 98 & 2 & -0.96 & 0.96 & -9.7 & $<<0.001$ \\
Chavela & 26 & 74 & 0.48 & 0.48 & 4.7 & $<<0.001$ \\
Margarita & 67 & 33 & -0.34 & 0.34 & -3.5 & $<<0.001$ \\
Neri & 98 & 2 & -0.96 & 0.96 & -9.7 & $<<0.001$ \\
Yayo & 79 & 21 & -0.58 & 0.58 & -5.9 & $<<0.001$
\end{tabular}

637 Note. L: Left-hand use. R: Right-hand use. HI: Handedness Index.

638 AbsHI: absolute value of the HI. 
639 Table 5

640 Hand preference of each individual in each of the four tasks

\begin{tabular}{llllll}
\hline & Sex & $\begin{array}{l}\text { Big } \\
\text { tube }\end{array}$ & $\begin{array}{l}\text { Small } \\
\text { tube }\end{array}$ & $\begin{array}{l}\text { Unimanual } \\
\text { tube }\end{array}$ & $\begin{array}{l}\text { Unimanual } \\
\text { reaching }\end{array}$ \\
\hline Brutus & $\mathrm{M}$ & $\mathrm{R}$ & $\mathrm{R}$ & $\mathrm{R}$ & $\mathrm{R}$ \\
Cejitas & $\mathrm{M}$ & $\mathrm{L}$ & $\mathrm{L}$ & $\mathrm{L}$ & $\mathrm{L}$ \\
Colin & $\mathrm{M}$ & $\mathrm{R}$ & $\mathrm{R}$ & $\mathrm{R}$ & $\mathrm{R}$ \\
Edgar & $\mathrm{M}$ & $\mathrm{L}$ & $\mathrm{L}$ & $\mathrm{L}$ & $\mathrm{L}$ \\
Frida & $\mathrm{F}$ & $\mathrm{R}$ & $\mathrm{R}$ & $\mathrm{R}$ & $\mathrm{R}$ \\
Karen & $\mathrm{F}$ & $\mathrm{L}$ & $\mathrm{R}$ & $\mathrm{L}$ & $\mathrm{A}$ \\
Kelly & $\mathrm{F}$ & $\mathrm{R}$ & $\mathrm{R}$ & $\mathrm{R}$ & $\mathrm{R}$ \\
Lucas & $\mathrm{M}$ & $\mathrm{R}$ & $\mathrm{R}$ & $\mathrm{R}$ & $\mathrm{R}$ \\
Mari & $\mathrm{F}$ & $\mathrm{R}$ & $\mathrm{R}$ & $\mathrm{R}$ & $\mathrm{R}$ \\
Paulina & $\mathrm{F}$ & $\mathrm{L}$ & $\mathrm{L}$ & $\mathrm{L}$ & $\mathrm{L}$ \\
Chavela & $\mathrm{F}$ & $\mathrm{L}$ & $\mathrm{L}$ & $\mathrm{L}$ & $\mathrm{R}$ \\
Margarita & $\mathrm{F}$ & $\mathrm{R}$ & $\mathrm{R}$ & $\mathrm{R}$ & $\mathrm{L}$ \\
Neri & $\mathrm{M}$ & $\mathrm{R}$ & $\mathrm{R}$ & $\mathrm{R}$ & $\mathrm{L}$ \\
Yayo & $\mathrm{M}$ & $\mathrm{L}$ & $\mathrm{L}$ & $\mathrm{L}$ & $\mathrm{L}$ \\
\hline & & & & & \\
\hline
\end{tabular}

641

642 Note. R: significant right-hand preference. L: significant left-hand preference.

643 A: ambidexter $=$ no significant preference for either hand

644 

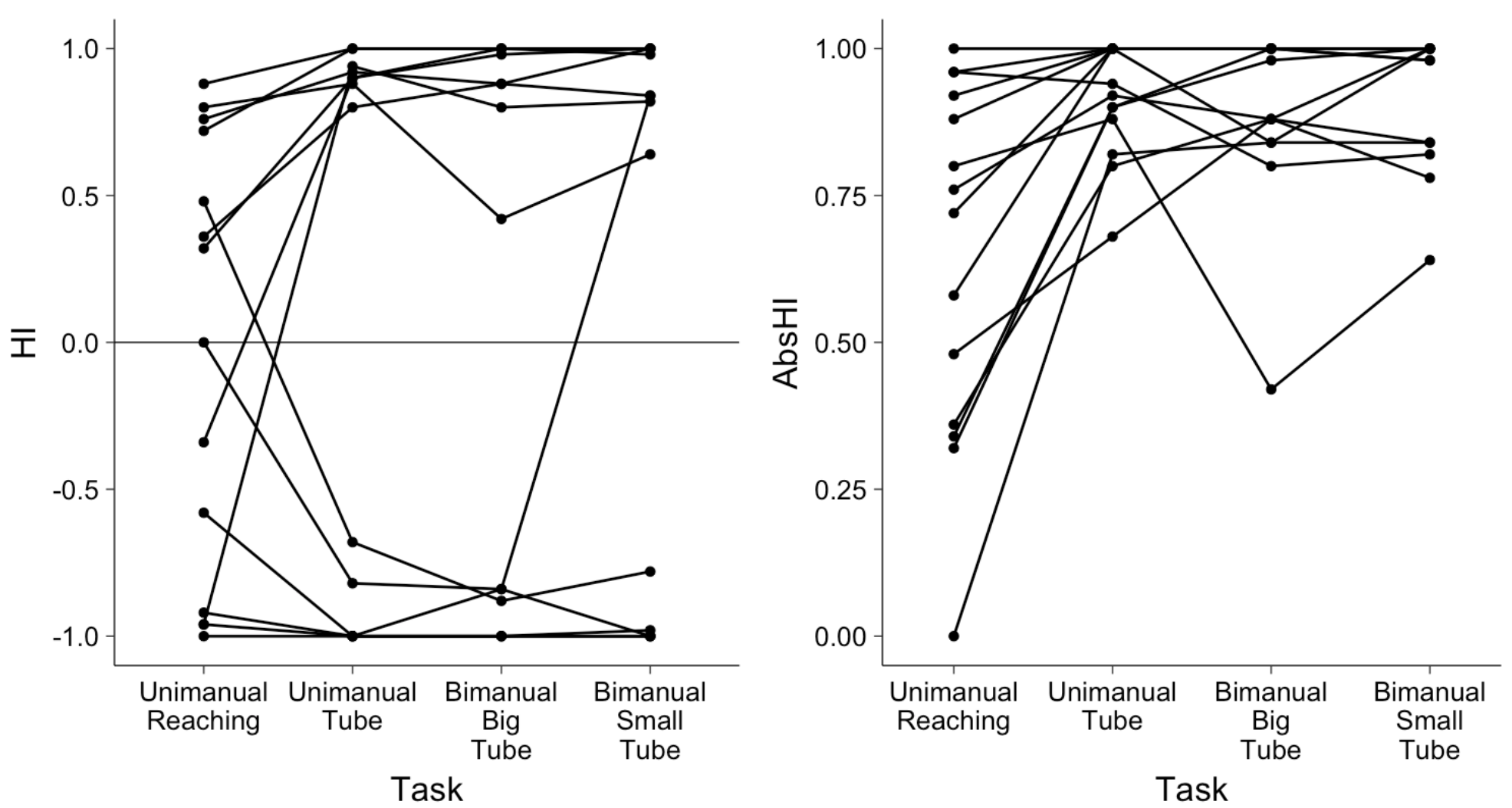

646

647 Figure 1. Individual HI scores (left panel) and AbsHI scores (right panel) in the four tasks.

648 Each line corresponds to one individual and the different data points correspond to the

649 individual values of direction (left) and strength (right) of hand preference in each of the four

650 tasks tested. 


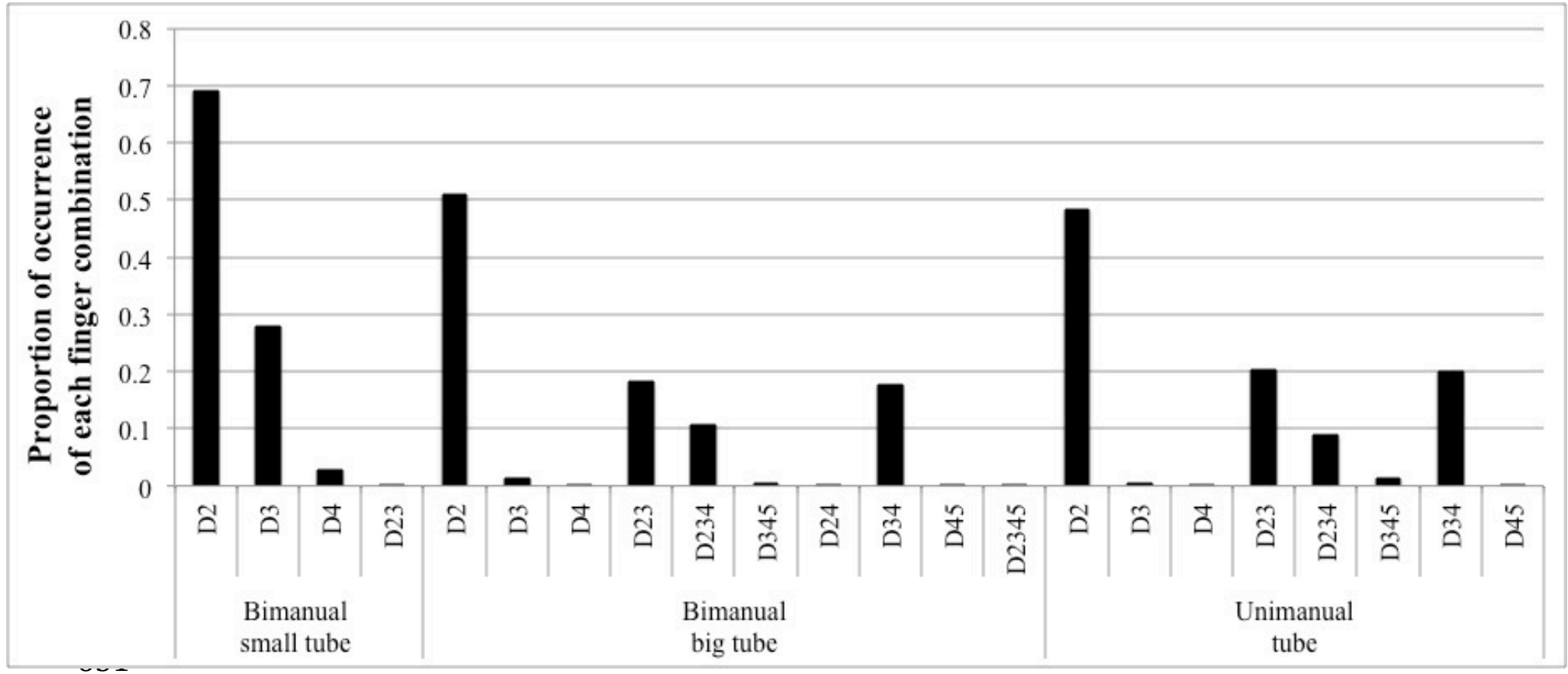

652 Figure 2. Comparison of use of the different finger combinations between the three tube 653 tasks. "D2", "D3" and "D4" indicate the index, middle, and ring finger, respectively. 